\title{
TNFR1-induced lethal inflammation is mediated by goblet and Paneth cell dysfunction
}

\author{
F Van Hauwermeiren ${ }^{1,2,5}$, RE Vandenbroucke ${ }^{1,2,5}$, L Grine ${ }^{1,2}$, S Lodens ${ }^{1,2}$, E Van Wonterghem ${ }^{1,2}$, \\ R De Rycke ${ }^{1,2}$, N De Geest ${ }^{3,4}, \mathrm{~B}$ Hassan $^{3,4}$ and C Libert ${ }^{1,2}$
}

Tumor necrosis factor (TNF) is a powerful activator of the immune system and a well-validated target for treatment of autoimmune diseases. Injection of TNF induces systemic lethal inflammation characterized by hypothermia, induction of multiple cytokines, and extensive damage to multiple organs. Previously, we reported that TNF-induced lethal inflammation is strictly TNFR1 (P55)-dependent. We also uncovered a crucial role for P55 expression levels in intestinal epithelial cells (IECs), in which P55 $+/+$ expression is sufficient to sensitize to TNF lethality in an otherwise fully protected P55 + I - background. Here, we investigated the molecular mechanism that drives TNF toxicity in IECs. Unexpectedly, we found that the degree of TNF-induced enterocyte damage and apoptosis in IECs is equally strong in TNF-sensitive P55 + / + mice and TNF-resistant P55 $+/$ - mice. Our results suggest that P55 $+/+$-induced signaling causes goblet and Paneth cell dysfunction, leading to severe epithelial barrier dysfunction. As a result, intestinal permeability and systemic bacterial spread are induced, causing lethal systemic inflammation. In conclusion, we identified P55-induced goblet and Paneth cell dysfunction as a crucial mechanism for TNF-induced systemic and lethal inflammation.

\section{INTRODUCTION}

Tumor necrosis factor (TNF) is a key regulator of immunity and an important mediator in septic shock ${ }^{1}$ and in autoimmune diseases such as arthritis and inflammatory bowel disease (IBD). ${ }^{2,3}$ Studies in animal models have indicated that TNF injection induces a systemic inflammatory response syndrome characterized by the induction of multiple toxic mediators such as interleukin (IL)-17, type I interferons, matrix metalloproteinases, and IL-1 $1{ }^{4-7}$ and the induction of hypothermia, hypotension, and multiple organ failure. ${ }^{8}$ TNF injection induces remarkably rapid effects on intestinal epithelial cells (IECs). Within $1 \mathrm{~h}$ after injection, TNF causes edema and extensive damage and apoptosis in the small intestine. ${ }^{9}$ This TNF model is useful to study acute inflammation such as sepsis, necrotizing enterocolitis, or intestinal hypoxia in addition to toxicity associated with systemic TNF/interferon- $\gamma$ administration for anticancer treatment. ${ }^{10-12}$

We recently reported that TNF-induced lethal inflammation is strictly TNFR1(P55) dependent. We found that P55+ I- mice, which express 50\% functional P55 levels in all tested cell types, are completely protected against TNF-induced lethal inflammation and resist doses of TNF up to $1 \mathrm{mg}$ that is 40 times higher than the $\mathrm{LD}_{100}$ (lethal dose 100\%) for P55 + / + mice. ${ }^{12}$ Furthermore, we provided evidence indicating that IECs are key targets in TNF-induced lethal inflammation. First, IEC-specific knockout of P55 led to significant protection against TNF lethality. Second, by using P55 reactivation mutant mice $\left(\mathrm{P} 55 \mathrm{cNeo}^{13}\right)$, we generated mice with a P55 + / - genetic (TNF resistant) background and Villin Cre-driven reactivation to a P55+/ + level specifically in the IECs that significantly restored the sensitivity to TNF. Although these results provide clear evidence for the involvement of the IECs in TNF-induced lethal inflammation, the precise intestinal epithelial cell type(s) and the molecular mechanism(s) involved in TNF-induced lethal inflammation remained unclear.

The intestinal epithelium consists of a single layer of cells that are continuously renewed by the crypt-residing stem cells. These stem cells give rise to four main specialized cell lineages:

\footnotetext{
${ }^{1}$ Inflammation Research Center, VIB, Ghent, Belgium. ${ }^{2}$ Department of Biomedical Molecular Biology, Ghent University, Ghent, Belgium. ${ }^{3}$ Department of Molecular and Developmental Genetics, Laboratory of Neurogenetics, VIB, Leuven, Belgium and ${ }^{4}$ Centre for Human Genetics, KU Leuven School of Medicine, Leuven, Belgium. Correspondence: C Libert (Claude.Libert@irc.VIB-UGent.be)

${ }^{5}$ The first two authors contributed equally to this work.
}

Received 12 June 2013; accepted 9 October 2014; published online 26 November 2014. doi:10.1038/mi.2014.112 
absorptive enterocytes and three secretory cell types: enteroendocrine, Paneth, and goblet cells. Among these cell types, enterocytes and goblet and Paneth cells have been recognized as crucial cell types in the maintenance of the intestinal barrier function. They perform critical functions in the maintenance of intestinal immune homeostasis by forming a mucus-covered physical barrier separating luminal bacteria and immune cells, and by expressing antimicrobial peptides. Dysfunction of either one of these cell types have been linked with increased susceptibility for, or spontaneous induction of, intestinal inflammation. ${ }^{14}$

Enterocytes make up $>80 \%$ of the epithelial cell layer and their main function is the absorption of nutrients. These cells also perform an important barrier function regulated by intercellular tight junctions that seal the epithelial layer and prevent bacterial infiltration and leakage of noxious substances (including bacterial toxins, digestive enzymes, and degraded food products) from the lumen. TNF, an intensely studied drug target for the treatment of IBD, is known to affect the enterocyte barrier function and is believed to do so by interfering with the regulation of tight junctions ${ }^{15}$ and/or by the induction of enterocyte apoptosis. ${ }^{9}$

Goblet cells are responsible for the production of multiple mucins (Muc 2, Muc 5AC, and Muc 6) as well as other molecules such as trefoil peptides, RELM $\beta$ (resistin-like molecule- $\beta$ ), and FCGBP (Fc Fragment of IgG binding protein) that are important functional components of the mucus barrier. ${ }^{16}$ This mucus layer is a physical barrier that protects the underlying IECs. ${ }^{17}$ It consists of different mucin proteins that form large crosslinked glycoproteins, prevent excessive Toll-like receptor triggering, and facilitate removal of adherent bacteria. ${ }^{18}$ Mucins are expressed and stored in granules in goblet cells from which they are continuously released. During inflammatory stimulation, accelerated mucus release can occur. ${ }^{19}$ Muc 2 has been identified as the major intestinal secreted mucin and primary component of the intestinal mucus layer. The importance of Muc 2 in the formation of an intact mucus layer was shown by experiments in Muc 2-deficient mice that have a defective barrier function and spontaneously develop colitis. ${ }^{20}$ Recently, it was reported that uptake of Muc 2coated bacteria by dendritic cells does not lead to inflammation but generates a tolerance signal through the production of regulatory T-cell growth factors such as IL-10, transforming growth factor- $\beta 1$, and retinaldehyde dehydrogenase. ${ }^{21}$

Paneth cells are located at the base of the crypts, adjacent to the intestinal stem cells. Besides their crucial role in supporting the stem cell niche, ${ }^{22}$ Paneth cells express several antibacterial peptides, such as $\alpha$-defensins and lysozyme, store them in apical-located granules, and release them within the mucus layer in response to bacterial stimuli. ${ }^{23}$ They actively sense bacteria and regulate the number of mucosa-associated bacteria. Paneth cell-depleted mice do not develop any spontaneous intestinal inflammation but they do show enhanced bacterial penetration to the mesenteric lymph nodes. ${ }^{24}$

Both goblet and Paneth cells are secretory cells that produce a high amount of essential proteins (e.g., mucins, defensins) that makes them susceptible to endoplasmic reticulum (ER) stress. ${ }^{17}$ Several reports indicate that mutations affecting ER stress regulation are strongly linked with intestinal pathology. ${ }^{25-27}$ In addition, autophagy was reported to play an important role in preventing intestinal inflammation, especially in Paneth cells, where autophagy prevents excessive inflammation because of unresolved ER stress. ${ }^{28}$

In this study, we investigated the TNF-stimulated, P55-driven molecular events responsible for the induction of systemic lethal inflammation, focusing on IECs by comparing TNF-sensitive P55 $+/+$ and Villin cre P55 $+/ \mathrm{cNeo}$ mice and TNF-resistant P55 $+/-$ mice.

\section{RESULTS}

TNF-induced IEC damage and apoptosis are not correlated with systemic TNF toxicity

P55 + / - mice display an extreme protection against acute TNF toxicity in contrast to $\mathrm{P} 55+/+$ mice, for which $\mathrm{LD}_{100}$ is $\sim 30 \mu \mathrm{g} .{ }^{29}$ We confirmed the resistance of $\mathrm{P} 55+/-$ mice against TNF-induced lethal inflammation by injecting $30 \mu \mathrm{g}$ TNF intraperitoneally in P55 $+/+(n=8)$ and in P55 $+/-$ mice $(n=8)$ (Figure 1a).

To identify the differences in TNF effects at the level of IECs between P55 $+/+$ and P55 $+I-$ mice, we performed hematoxylin and eosin staining of ileum samples taken $0,1,4$, and $8 \mathrm{~h}$ after intraperitoneal injection of $30 \mu \mathrm{g}$ of TNF. Visually, the intestinal damage in P55 $+/+$ and P55 $+/-$ mice was equally severe (Figure 1b). We quantified intestinal damage by a validated method that considers villus height, epithelial cell death at the villus top, and detachment from the lamina propria. ${ }^{30}$ Four observers blinded to the identities of the slides found no difference between TNF-induced damage in $\mathrm{P} 55+/+$ and P55 $+/$ - samples (Figure 1c). The damage $4 \mathrm{~h}$ after TNF injection was confirmed by transmission electron microscopy (TEM) in both genotypes (Supplementary Figure S1 online). In contrast to the well-organized cylindrical enterocytes with basally located nuclei in untreated mice, TNF induced considerable disorganization of the enterocytes at the top of the villi in both P55 $+/+$ and P55 $+/$ - mice. This disorganization was characterized by disturbed morphology and location of the nuclei, and appearance of swollen, dying cells filled with small vacuoles.

Next, we stained sections with TUNEL (terminal deoxynucleotidyl transferase dUTP nick end labeling) to detect apoptotic cells (Figure 1d). A comparable amount of TUNELpositive cells was detected in $\mathrm{P} 55+/+$ and $\mathrm{P} 55+/-$ mice (Supplementary Figure S1B). In a separate experiment, we collected and counted the luminal apoptotic cells ${ }^{9}$ from $\mathrm{P} 55+/+$ and P55 $+/-$ mice $4 \mathrm{~h}$ after treatment with TNF and from untreated controls. The amount of luminal cells was similar in $\mathrm{P} 55+/+$ and $\mathrm{P} 55+/-$ mice (Supplementary Figure S1C). Caspase-3/7 activity, a hallmark of apoptotic cell death, was measured by DEVD assay on ileal lysates of $\mathrm{P} 55+/+$ and $\mathrm{P} 55+/-$ mice $4 \mathrm{~h}$ after TNF injection. This assay revealed no difference in ileal caspase-3/7 activity, 

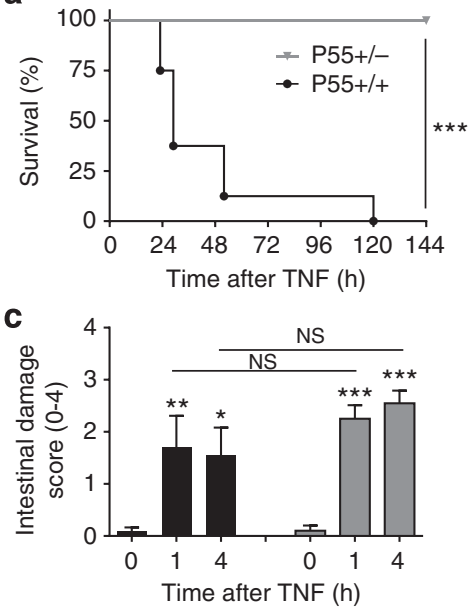

b

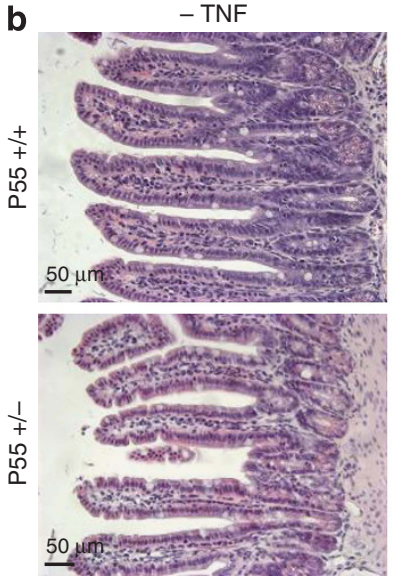

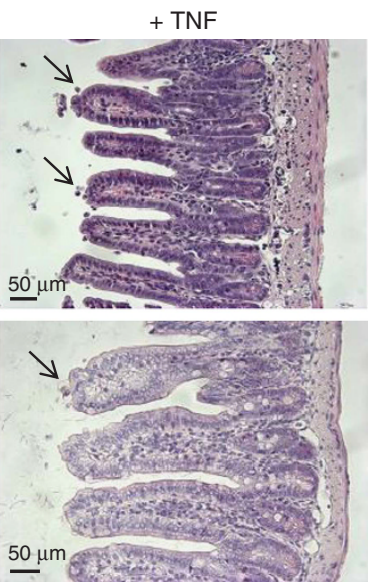

d
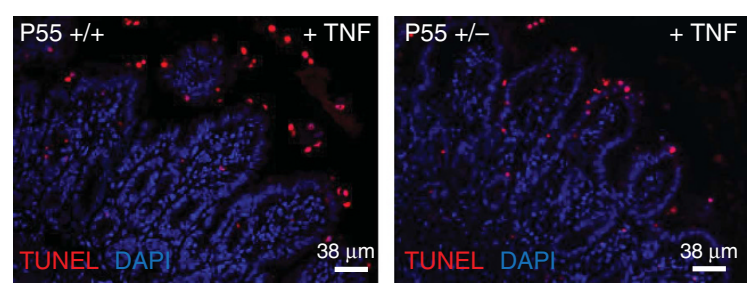

e
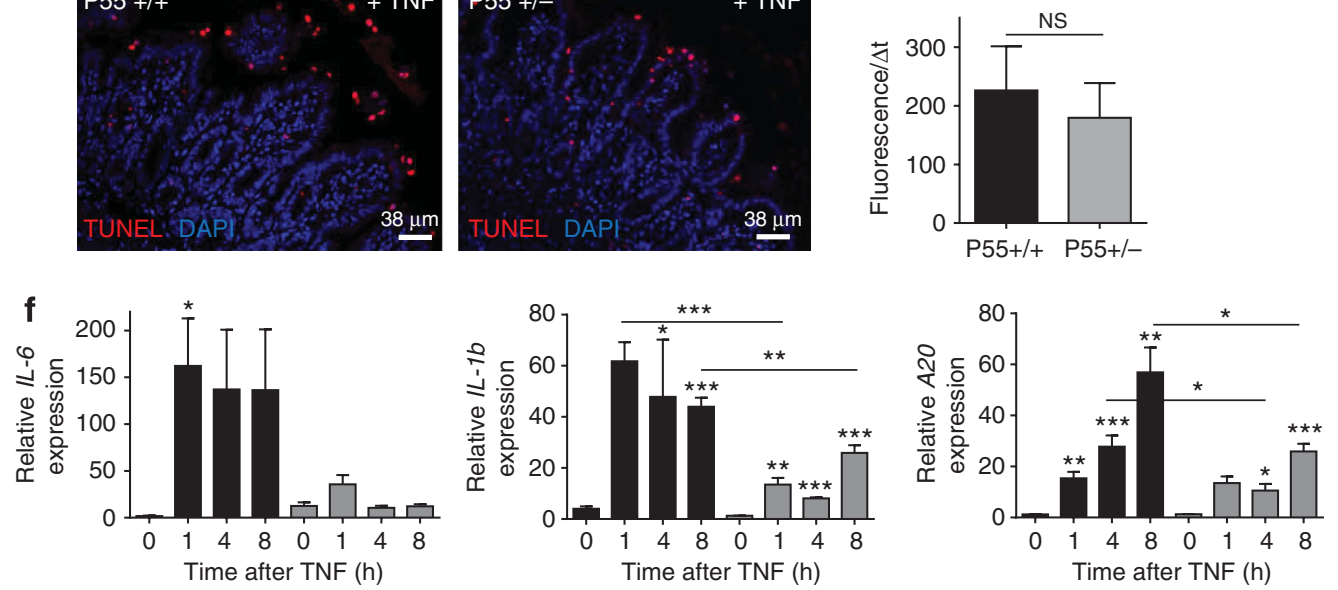

Figure 1 Inflammation and intestinal epithelial cell (IEC) damage in P55 $+/+$ and P55 $+/-$ mice after tumor necrosis factor (TNF) challenge. (a) Survival of P55 $+/+$ (black, $n=8$ ) and P55 $+/$ - (gray, $n=8$ ) after injection with $30 \mu \mathrm{g}$ TNF. (b) Hematoxylin and eosin (H\&E) staining of P55 $+/+$ and P55 + / - sections of the ileum, untreated (two left panels) and $8 \mathrm{~h}$ after TNF challenge (two right panels). TNF induces marked shortening of the villi and cell death at the tops of the villi (arrows). (c) Damage score of the H\&E staining on ileal sections of P $55+/+$ (black) and P55 $+/-($ gray) mice ( $n=5$ for all samples) at different time points, scored by four neutral observers. (d) Representative TUNEL staining of apoptotic cells on ileal sections. Similar amounts of apoptotic cells are detected in P55 $+/+$ and P $55+/$ - samples at 1, 4, and 8 h after TNF challenge, the 8-h time point is shown here ( $n=4-5)$. (e) Caspase-3/7 activity measurement by DEVD assay in ileal lysates of P55 $+/+$ (black) and P55 $+/-($ gray) mice $(n=8) 4 \mathrm{~h}$ after TNF injection expressed in increase in fluorescence over time. (f) Quantitative real-time PCR (qPCR) analysis of induction of nuclear factor (NF)-kB-driven genes in ileum samples of P55 + I+ (black) and P55 + / - (gray) mice injected with $30 \mu \mathrm{g} \mathrm{TNF} \mathrm{(} n=4$ per time point). DAPI, 4',6-diamidino-2-phenylindole; IL, interleukin; NS, not significant; TUNEL, terminal deoxynucleotidyl transferase dUTP nick end labeling. ${ }^{\star} 0.01 \leq P<0.05 ;{ }^{* \star} 0.001 \leq P<0.01 ;{ }^{* \star \star} P<0.001$.

confirming equal induction of apoptosis in the ilea of TNFinjected P55 $+/+$ and P55 $+/-$ mice (Figure 1e).

On the other hand, gene expression patterns in intestinal lysates of mice injected with TNF revealed significantly less induction of the nuclear factor (NF)- $\kappa \mathrm{B}$-dependent gene products $I L-6, I L-1 \beta$, and $A 20$ in $\mathrm{P} 55+/-$ mice than in $\mathrm{P} 55+/+$ mice (Figure 1f).

\section{Induction of intestinal permeability is correlated with TNF toxicity and lethality}

The induction of intestinal permeability was investigated by oral gavage of fluorescently labeled $4 \mathrm{kDa}$ dextran in TNFinjected P55 $+/+$ and P55 $+/-$ mice, followed by measurement of the fluorescence in the plasma. ${ }^{31}$ At $8 \mathrm{~h}$ after TNF injection, a significant increase in intestinal permeability was observed in $\mathrm{P} 55+/+$ mice but not in $\mathrm{P} 55+/-$ mice (Figure 2a). In our previous work, we reported that TNF can induce a strong increase in intestinal permeability in $\mathrm{P} 55+/-$ mice provided that they express normal P55 $+/+$ levels in IECs. ${ }^{29}$ These data indicate that TNF has a direct effect on $\mathrm{P} 55+/+$ IECs leading to intestinal permeability.

We hypothesized that intestinal leakage leads to the release of bacteria from the intestine into the circulation, causing systemic inflammation as described by Goldman et al. ${ }^{32}$ from studies on TNF-injected rats. Quantification of bacterial growth in lysates of liver, lung, and mesenteric lymph nodes confirmed the occurrence of TNF-induced bacterial translocation. TNF-injected $\mathrm{P} 55+/+$ and $\mathrm{P} 55+/-$ mice displayed 


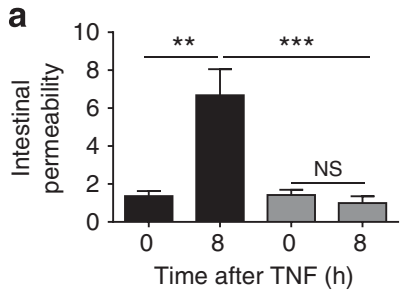

e

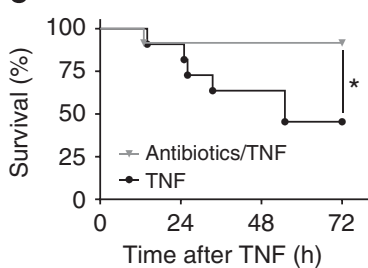

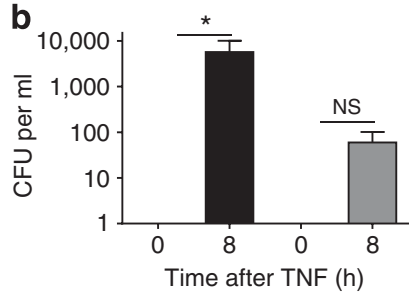
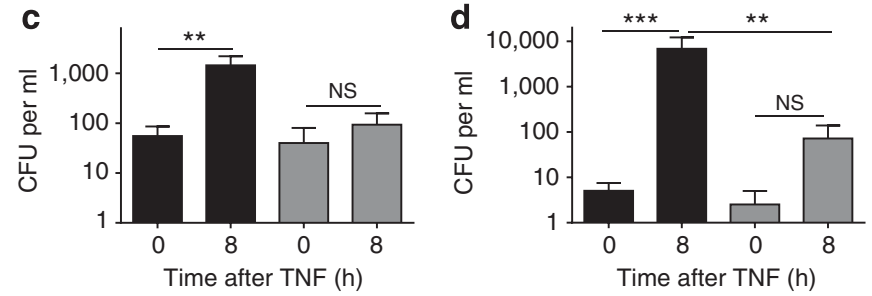

f
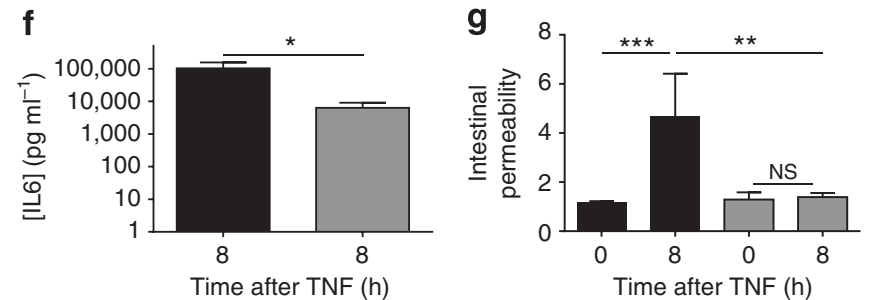

Figure 2 Intestinal permeability and involvement of the intestinal flora in tumor necrosis factor (TNF)-induced lethal inflammation. (a) Measurement of intestinal permeability, expressed as relative increase in fluorescence in plasma of P55 + / + (black) and P55 + / - mice (gray), orally gavaged with $4 \mathrm{kDa}$ fluorescein isothiocyanate (FITC)-dextran and injected with $30 \mu \mathrm{g} \mathrm{TNF}(n \geq 9$ for TNF-injected P55 $+/+$ (black) and P55 $+/-$ (gray) mice and $n \geq 4$ for untreated mice). (b-d) Bacterial growth in lysates of (b) liver, (c) lung, and (d) mesenteric lymph nodes, isolated from P55 $+/+$ (black) and P55 $+/-$ (gray) mice ( $n \geq 6$ for all groups), $18 \mathrm{~h}$ after injection with phosphate-buffered saline (PBS) or $30 \mu \mathrm{g}$ TNF. (e) Survival of mice, either untreated (black, $n=11$ ) or pretreated with broad-spectrum antibiotics (gray, $n=12$ ), and then challenged with $30 \mu \mathrm{g}$ TNF. (f) Interleukin-6 (IL-6) measurement in the serum of untreated mice (black, $n=3$ ) or from mice pretreated with broad-spectrum antibiotics (gray, $n=3$ ) $6 \mathrm{~h}$ after TNF challenge. (g) Measurement of intestinal permeability, expressed as relative increase in fluorescence, in plasma of untreated (black) or antibiotics-treated mice (gray), orally gavaged with $4 \mathrm{kDa}$ FITC-dextran and then injected with TNF $(n=7)$. CFU, colony-forming unit; NS, not significant. ${ }^{*} 0.01 \leq P<0.05$; ${ }^{\star *} 0.001 \leq P<0.01$; ${ }^{\star * \star} P<0.001$.

more bacterial contamination than phosphate-buffered saline (PBS)-injected mice, but P55 $+/-$ mice showed significantly less bacterial influx than P55 $+/+$ mice (Figure 2 b-d).

We then investigated the role of intestinal flora as a mediator of TNF toxicity by treating P55 $+/+$ mice with a cocktail of broad-spectrum antibiotics, as previously described. ${ }^{33}$ After a week of treatment, microbial sterility of the mice was confirmed by overnight cultures of feces under both aerobic and anaerobic conditions (not shown). Antibiotics-treated $\mathrm{P} 55+/+$ mice were significantly protected against TNF lethality and showed lower IL-6 serum levels (Figure 2e,f). Interestingly, antibiotics also prevented the increase in intestinal permeability (Figure 2g), suggesting that a combination of both P55 signaling and bacterial stimulation is necessary for the induction of intestinal permeability.

\section{TNF induces goblet cell dysfunction}

Alcian blue $(\mathrm{AB})$ staining of ileal tissue sections indicated that although basal levels of goblet cells were identical in P55 $+/+$ and P55 $+/-$ mice, TNF significantly depleted mucus granules in goblet cells in $\mathrm{P} 55+/+$ mice but not in P55 + / - mice (Supplementary Figure S2A). This finding was confirmed by specific Muc 2 immunofluorescence staining that revealed a large reduction of Muc 2 in IECs of P55 $+1+$ mice after TNF administration, but not in $\mathrm{P} 55+/-$ mice (Figure 3a).

To further illustrate this mucus depletion in goblet cells, we measured the size and number of goblet cell granules in $\mathrm{P} 55+/+$ and P55 $+/-$ mice by automated analysis of ABstained sections with Volocity software. The number of goblet cells in P55 $+/+$ intestines was significantly reduced $8 \mathrm{~h}$ after
TNF injection, whereas it remained unchanged in P55 $+/-$ mice (Supplementary Figure S2B). In addition, the size distribution of goblet cell granules shows that the remaining $\mathrm{P} 55+/+$ goblet cells contain fewer mucus, whereas the mucus content of P55 $+/-$ goblet cells is unaffected in response to TNF (Supplementary Figure S2C).

Detailed analysis of TEM sections showed that $8 \mathrm{~h}$ after TNF injection the ER in the goblet cells of P55 $+/+$ mice had become disorganized and dilated (Supplementary Figure S2D). In addition, many of the mitochondria have a dilated phenotype, indicating mitochondrial damage (Supplementary Figure S2E). These TNF-induced effects were not observed in P55 + / - goblet cells that retained a normal and structured appearance after TNF injection with no abnormalities in ER and mitochondria, suggesting that P55 signaling is involved in goblet cell dysfunction (Figure $\mathbf{3 b}$ ).

The induction of ER stress in goblet cells was further examined in the goblet cell line HT-29-MTX. ${ }^{34}$ The in vitro TNF stimulation of these cells increased the expression of several genes related to ER stress, such as BiP, spliced $X B P 1$, and IRE1 (Figure 3c). Transfection with P55-targeting small interfering RNA (siRNA) significantly reduced the induction of these ER stress markers compared with transfection with control siRNA (Figure 3d). These results indicate that TNF can directly induce ER stress in goblet cells in a P55-dependent manner.

Interestingly, IEC-specific reactivation of P55 to a P55 $+/+$ level in P55 $+/-$ mice (Villin Cre P55 $+/$ cNeo mice) led to a reduction in mucus-containing goblet cells and Muc 2 content after TNF injection, indicating that the mucus-depleting effect of TNF on IECs is a direct P55-mediated phenomenon 
a

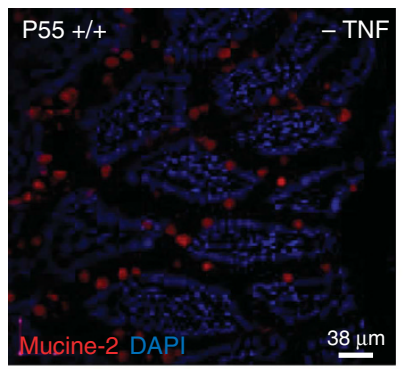

P55 +/-
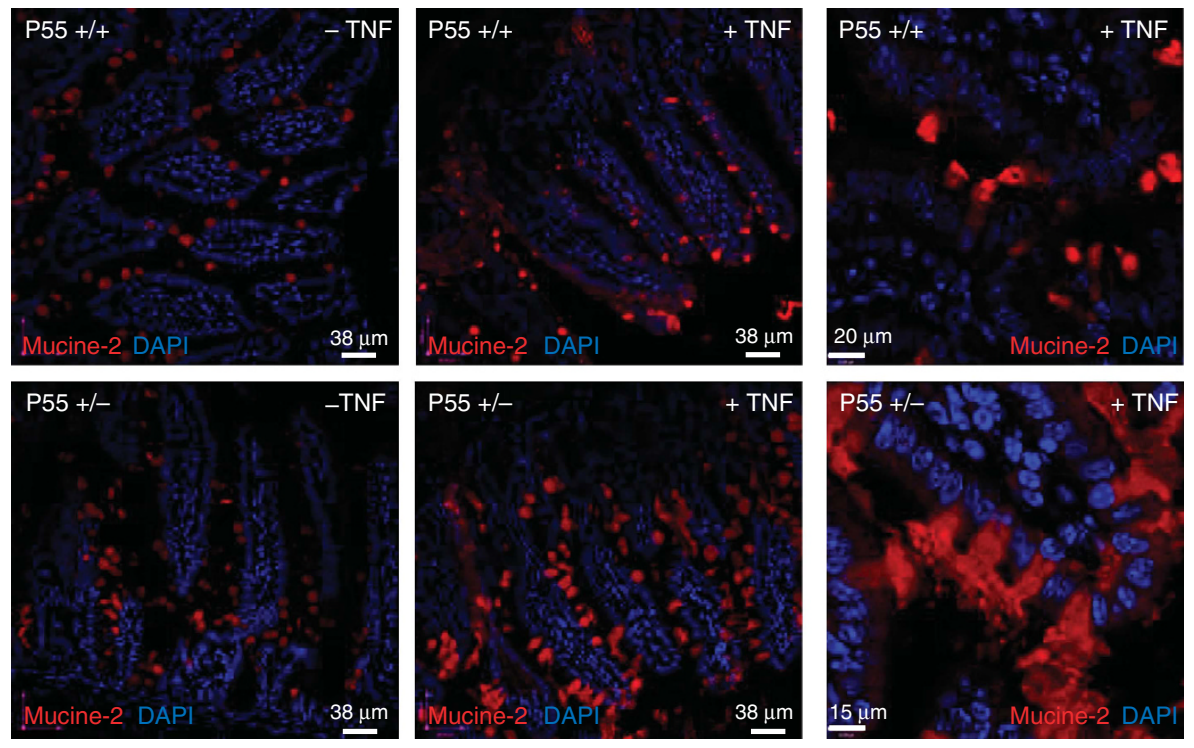

b $\mathrm{P} 55+/+$ untreated
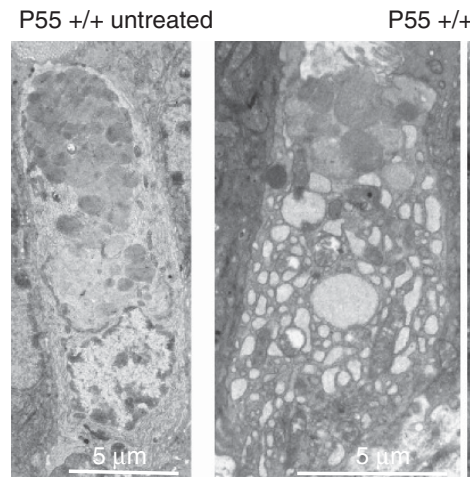

P55 +/+ 8 h TNF
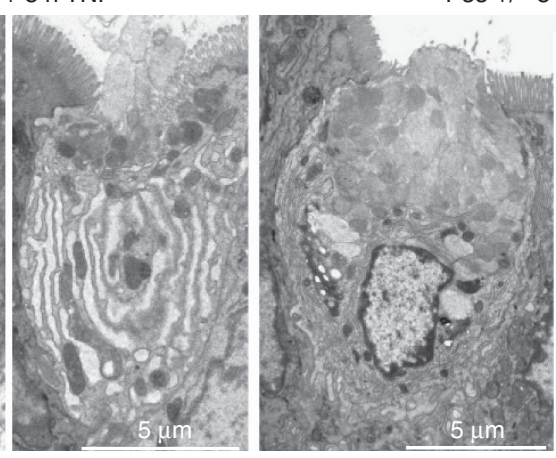

P55 +/- 8 h TNF
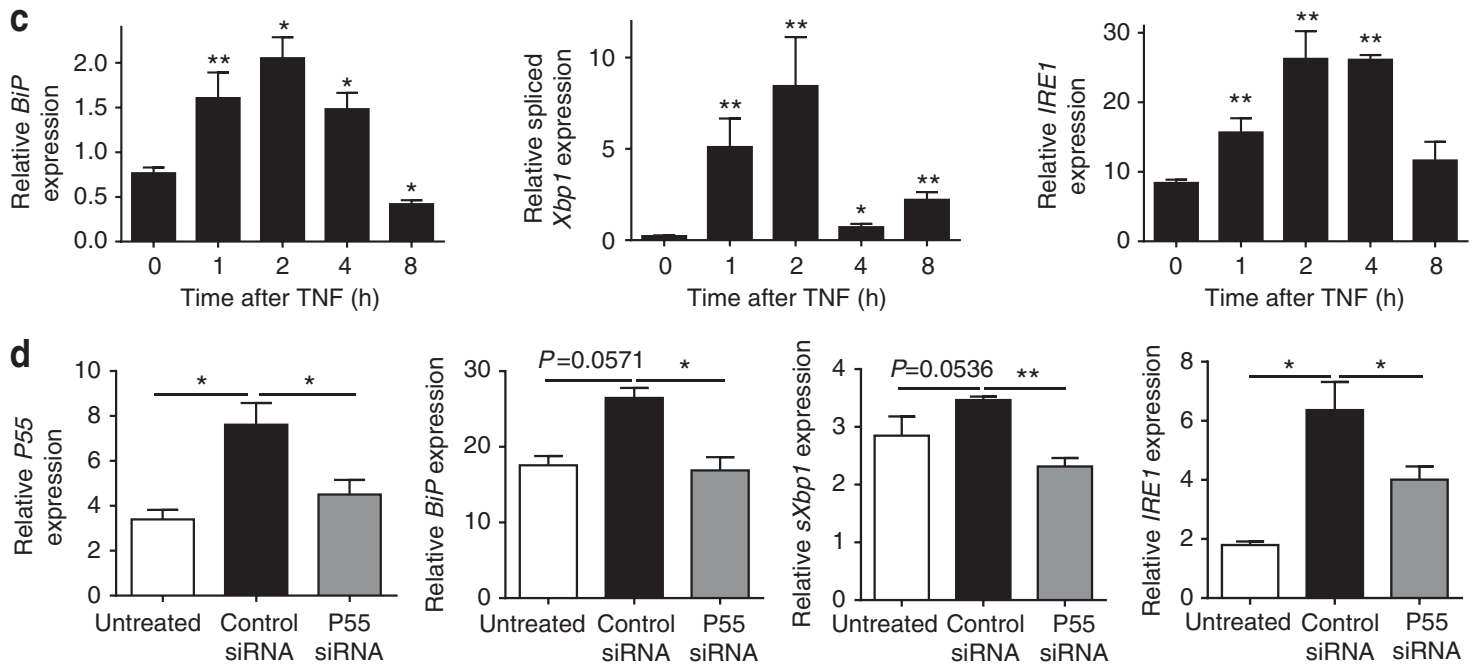

Figure 3 Analysis of goblet cell mucus content after tumor necrosis factor (TNF) challenge in P55 $+/+$ and P55 $+/-$ mice. (a) Immunofluorescent Muc 2 stainings (red), counterstained with 4',6-diamidino-2-phenylindole (DAPI; blue) on ileal sections of P55 + / + (upper panels) and P55 + / - mice (lower panels) $8 \mathrm{~h}$ after challenge with $30 \mu \mathrm{g}$ TNF. (b) Transmission electron microscopy (TEM) images of representative goblet cells in the ileum of $\mathrm{P} 55+/+$ and P55 $+/-$ mice untreated or $8 \mathrm{~h}$ after $30 \mu \mathrm{g}$ TNF challenge. Depletion of mucus granules (dotted red line) and dilated and disorganized endoplasmic reticulum (ER) can be observed in P55 + / but not in P55 + / - goblet cells. (c) Quantitative real-time PCR (qPCR) analysis of ER stressregulating genes in HT-29 MTX goblet cells stimulated for 1, 2, 4, and $8 \mathrm{~h}$ with 2,000 U ml ${ }^{-1} \mathrm{TNF}$ ( $n=5$ for all samples). (d) Effect of P55 knockdown on TNF-induced ER stress in HT-29 MTX goblet cells. Cells were either left untreated or transfected with control or P55 small interfering RNA (siRNA) and stimulated with TNF for $6 \mathrm{~h}$. Next, mRNA was isolated and P55 expression and ER stress-regulated genes were measured by qPCR ( $n=6$ for all samples). ${ }^{\star} 0.01 \leq P<0.05 ;{ }^{\star *} 0.001 \leq P<0.01 ;{ }^{\star \star \star} P<0.001$. 

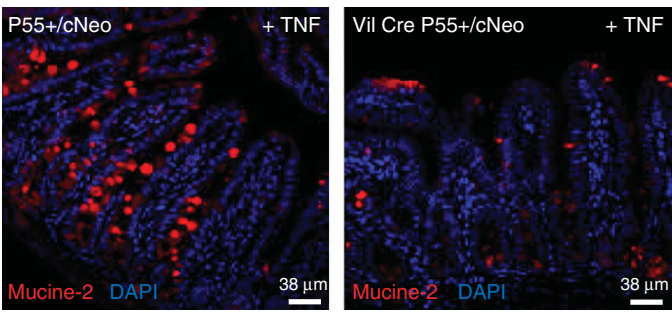

b

Vil Cre P55 +/cNeo 8 h TNF

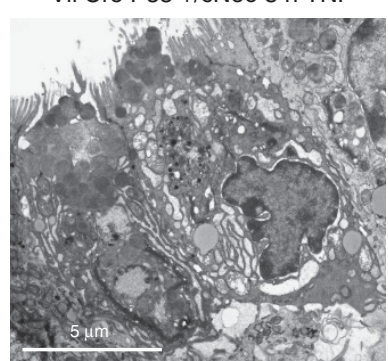

Figure 4 Analysis of goblet cell mucus content after tumor necrosis factor (TNF) challenge in Villin (Vil) Cre P55+/cNeo mice. (a) Immunofluorescent Muc 2 stainings (red) counterstained with 4',6-diamidino-2-phenylindole (DAPI; blue) on ileal sections of P55 +/cNeo and Villin Cre P55 +/cNeo mice $8 \mathrm{~h}$ after challenge with $30 \mu \mathrm{g}$ TNF. (b) Transmission electron microscopy (TEM) image of a representative goblet cell in the ileum of Villin Cre P55 +/cNeo mice $8 \mathrm{~h}$ after $30 \mu \mathrm{g}$ TNF challenge. Depletion of mucus granules and dilated and disorganized endoplasmic reticulum (ER) can be observed.

(Figure 4a and Supplementary Figure S3A-C). Similarly, TEM images taken from IEC sections of Villin Cre P55 $+/ \mathrm{cNeo}$ mice $8 \mathrm{~h}$ after TNF injection display signs of ER stress and mitochondrial swelling in goblet cells to a similar degree as observed in goblet cells of P55 $+/+$ mice (Figure $4 \mathbf{b}$ ).

Standard paraformaldehyde fixation washes away the watersoluble mucus, and hence we repeated the Muc 2 stainings on Carnoy-fixed tissues to visualize the adhered mucus layer. In contrast to the thick, firmly adhered, mucus layer in the colon, the mucus layer in the small intestine is thinner and rather patchy. We used stacks of confocal microscopy images to properly visualize the mucus layer in the small intestine. Muc 2 immunostaining $8 \mathrm{~h}$ after TNF revealed a defective mucus layer in $\mathrm{P} 55+/+$ and Villin Cre $\mathrm{P} 55+/ \mathrm{cNeo}$ mice in contrast to the P55 $+/-$ mice. The latter maintain a thicker and better preserved protective mucus layer (Supplementary Figure S4A). We performed Muc 2 (green) and bacterial fluorescence in situ hybridization (red) co-stainings. Remarkably, TNF injection causes a near-complete depletion of bacteria in the lumen of the small intestine in all genotypes, probably because of excessive mucus release, edema, and diarrhea. However, in the TNF-injected P55 $+/+$ and Villin Cre $\mathrm{P} 55+/ \mathrm{cNeo}$ mice, we observed bacteria that penetrated the IEC layer and this was not observed in untreated mice and TNF-treated P55 $+/-$ mice (Supplementary Figure S4B,C).

\section{TNF induces Paneth cell dysfunction}

The effect of TNF on Paneth cells was investigated $8 \mathrm{~h}$ after TNF injection in P55 $+/+$, Villin Cre P55 $+/$ cNeo, and P55 $+/-$ mice by TEM analysis. Paneth cells of TNF-injected P55 $+/+$ and Villin Cre P55 $+/ \mathrm{cNeo}$ mice contained dilated and disorganized ER (Figure 5a), dilated mitochondria (Figure 5b), autophagic vacuoles containing ER and other cytoplasmic organelles (Figure 5c), and smaller electron-dense structures of unknown nature (Figure 5d). In addition, we observed multiple Paneth cells with loss of cellular integrity, releasing membrane-encapsulated clumps of cells or free cytosolic organelles into the crypt lumen (Figure 5e and Supplementary Figure S5A-C). Crypts from P55 + / - mice showed an overall better preserved morphology with no loss of integrity and no abnormalities in the ER and mitochondria, although the smaller electron dense structures and autophagic vacuoles could also be observed in some of the P55 + / - crypts but with lower frequency and lower severity. To check the functionality of the Paneth cells we performed a lysozyme C immunostaining. P55 $+/+$ mice lost almost all lysozymepositive granules in the Paneth cells after TNF injection, whereas the Paneth cells of the TNF-injected P55 $+/-$ mice retained lysozyme C-positive granules (Figure $5 \mathbf{f}$ and Supplementary Figure S5D). This was also confirmed by quantification of the total amount of Paneth cell granules using light microscopy. Indeed, analysis of semi-thin sections revealed a significant decrease in Paneth cell granules after TNF injection in P55 + / + crypts that was absent in P55 + / mice (Supplementary Figure S5E and Figure 5g).

\section{Depletion of Paneth and goblet cells sensitizes for TNF- induced toxicity}

To investigate the importance of Paneth and goblet cells in TNF-induced toxicity we made use of the P450 Cre Math1 flx/ flx mice. Math1 is a transcription factor with an essential role in the generation of secretory IECs. Injection of $\beta$-naphtoflavone causes Math1 deficiency that leads to depletion of goblet, Paneth, and enteroendocrine cells. ${ }^{35}$ Depletion of goblet cells was analyzed by $\mathrm{AB}$ staining and lysozyme $\mathrm{C}$ staining was used to detect Paneth cells (Supplementary Figure S6A,B). This revealed a $>90 \%$ reduction of goblet and Paneth cells that is similar to earlier reports. ${ }^{35}$ When these mice were challenged with a normally nonlethal dose of TNF they show an increased sensitivity for TNF-induced toxicity, characterized by increased hypothermia (Figure 6a), lethality (Figure 6b), and intestinal permeability (Figure 6c).

In addition, we made use of pilocarpine, a cholinergic agonist that induces fast mucus depletion ${ }^{36}$ and that reduces intestinal motility, an effect that is also observed upon TNF signaling in the intestine. ${ }^{37}$ Pretreatment of mice with pilocarpine significantly sensitized mice to TNF so that a normally nonlethal dose of TNF caused considerable mortality in both $\mathrm{P} 55+/+$ and P55 $+/-$ mice (Figure $\mathbf{6 c}, \mathbf{d}$ ). These data illustrate that 
a

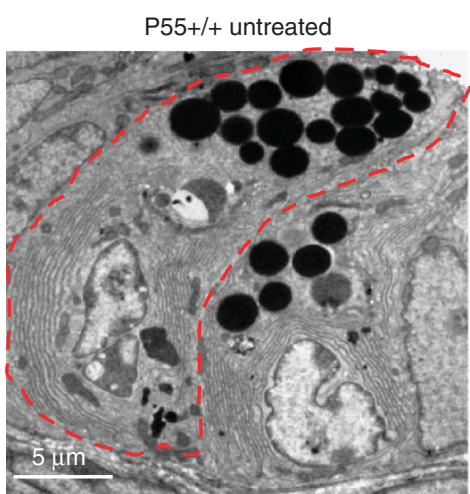

b

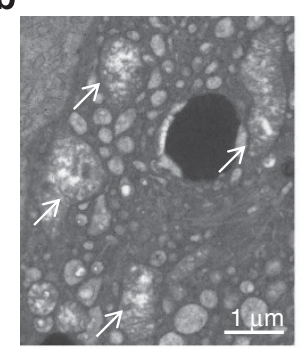

$c$
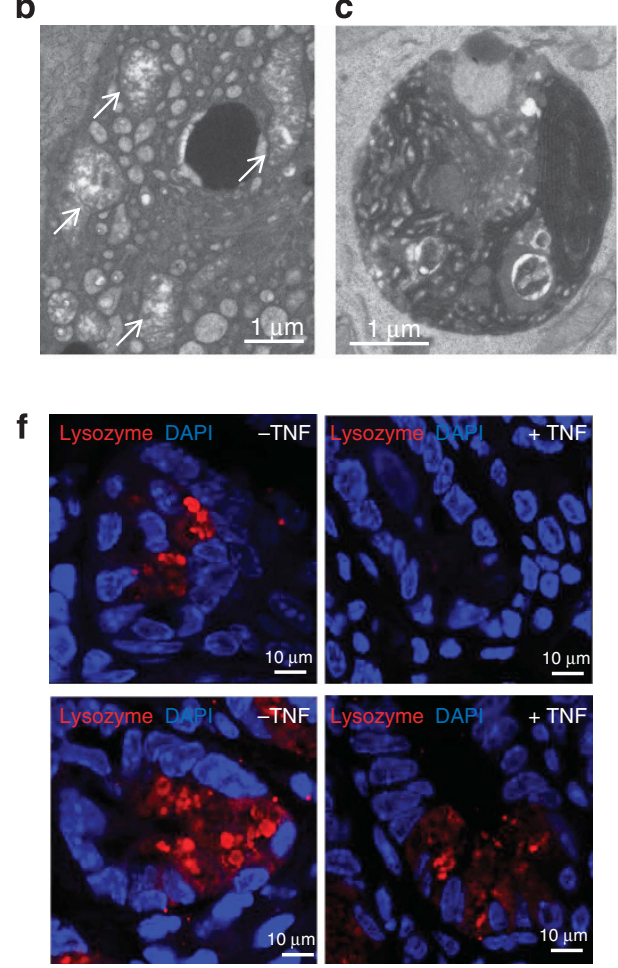

P55+/+ 8 h TNF

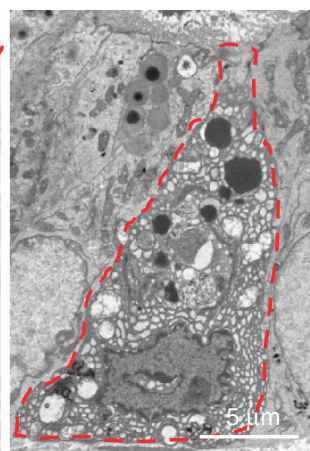

d

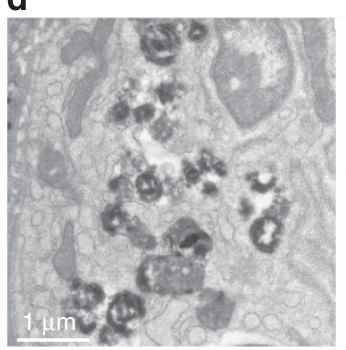

Vil Cre P55+/- 8 h TNF P55 +/cNeo 8 h TNF
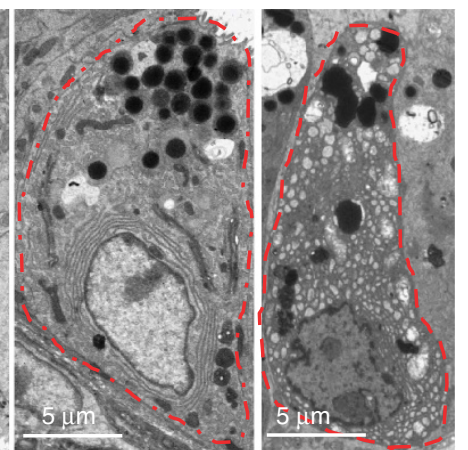

e

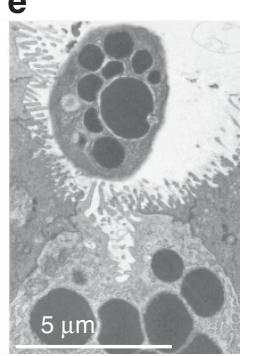

g

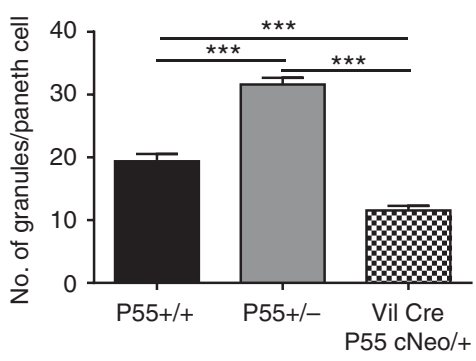

Figure 5 Tumor necrosis factor (TNF)-induced effects on Paneth cells. (a) Transmission electron microscopy (TEM) images of representative Paneth cells in the ileum of P55 + / , P55 +/ - , and Villin (Vil) Cre P55 +/cNeo mice untreated or $8 \mathrm{~h}$ after $30 \mu \mathrm{g}$ TNF challenge. A single Paneth cell is circled by a dotted red line. (b-e) TEM images of observed abnormalities in the Paneth cells of P55 $+/+$ and Villin Cre P55 + /cNeo mice. (b) Dilated mitochondria. (c) Autophagic vacuoles. (d) Small electron-dense structures. (e) Loss of cellular integrity. (f) Lysozyme immunostaining in Paneth cells of P55 $+/+$ and P55 $+/$ - mice in either untreated or $8 \mathrm{~h}$ TNF-treated condition. (g) Quantification of the number of granules in Paneth cells $8 \mathrm{~h}$ after TNF challenge in $\mathrm{P} 55+/+$ (black) and P55 + / - (gray) and Vil Cre P $55+/$ cNeo ileal sections, counted on representative images by a neutral observer $(n=2$ mice per genotype, $\geq 8$ images per mouse). DAPI, 4',6-diamidino-2-phenylindole. ${ }^{\star} 0.01 \leq P<0.05 ;{ }^{\star *} 0.001 \leq P<0.01 ;{ }^{* \star *} P<0.001$.

goblet cells (and Paneth cells) have protective roles against an acute inflammatory challenge with TNF.

\section{Dexamethasone pretreatment reduces TNF-induced IEC effects}

To investigate whether P55-activated proinflammatory signals are involved in the IEC dysfunction induced by TNF, we pretreated mice with the synthetic glucocorticoid dexamethasone (DEX), a well-known anti-inflammatory drug that significantly protects mice against a lethal dose of $\mathrm{TNF}^{38,39}$
(Supplementary Figure S7A). We focused on the effects of DEX/TNF treatment on IECs. Again, we observed that mice treated with DEX/TNF or with TNF alone had similar damage and induction of apoptosis (Supplementary Figure S7B), further strengthening the idea that TNF-induced apoptosis is not necessarily linked with TNF toxicity and/or lethality. However, by using $A B$ and Muc 2 immunostainings we observed that DEX pretreatment significantly protected against TNF-induced mucus depletion in goblet cells of mice treated with TNF (Figure 7a,b). In agreement with this, TEM analysis 

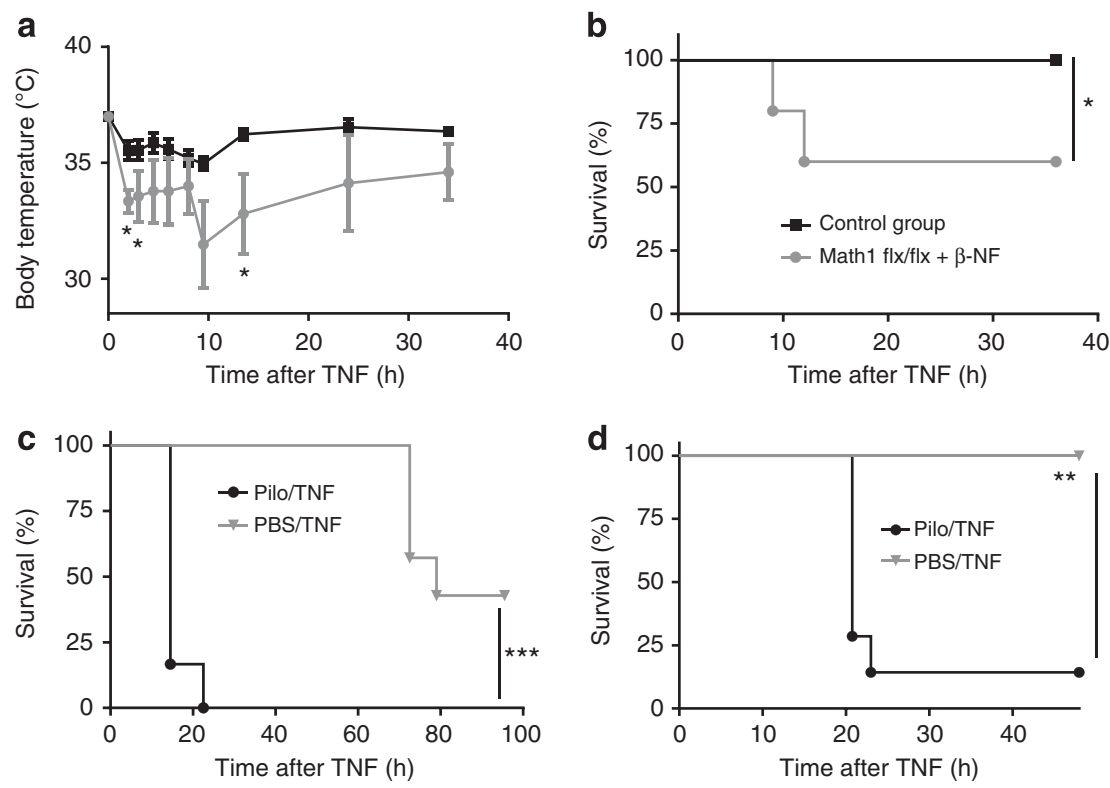

Figure 6 Goblet and/or Paneth cell depletion sensitizes for tumor necrosis factor (TNF) toxicity. (a-c) Math1 deficiency sensitizes for TNF toxicity. (a) Body temperature of Math1-depleted mice ( $\beta$-naphtoflavone ( $\beta$-NF)-treated $P 450$ Cre Math1 flx/flx mice $(n=5))$ compared with control mice $(n=10)$, including vehicle-treated Math1 flx/flx mice $(n=5)$ and $\beta$-NF-treated Math1 $+/+$ mice $(n=5)$, after injection with $7.5 \mu \mathrm{g}$ TNF. (b) Survival of Math1depleted mice and control mice after injection with a normally nonlethal dose of $12.5 \mu \mathrm{g}$ TNF. (c, d) Pretreatment with pilocarpine (Pilo), a mucus-depleting agent, sensitizes mice to TNF-induced toxicity. (c) P55 $+/+$ mice pretreated with pilocarpine $(n=6)$ display a significant higher lethality after a normally nonlethal $15 \mu \mathrm{g}$ TNF injection compared with phosphate-buffered saline (PBS)-pretreated mice $(n=7)$. (d) The TNF-resistant P55 + / - mice $(n=7)$ can be sensitized to a normally nonlethal $50 \mu \mathrm{g}$ TNF injection by pretreatment with pilocarpine $(n=7) .{ }^{*} 0.01 \leq P<0.05 ;{ }^{* *} 0.001 \leq P<0.01 ;{ }^{* * *} P<0.001$.

a
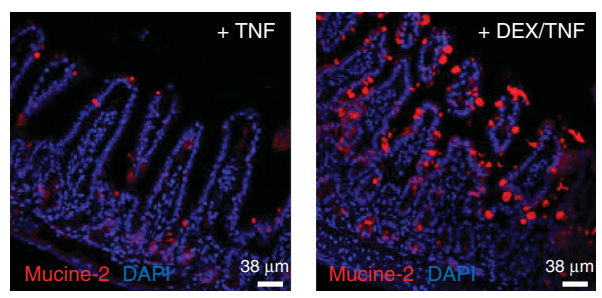

C

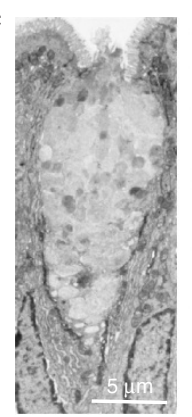

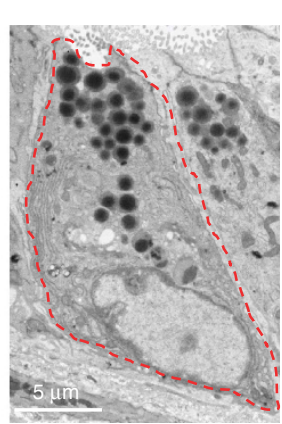

d

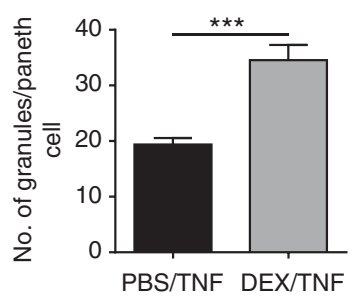

b

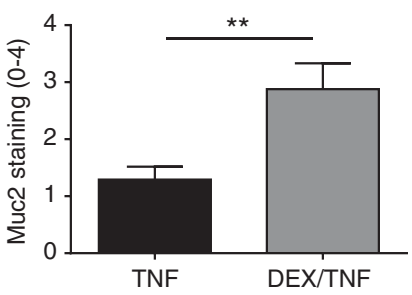

e

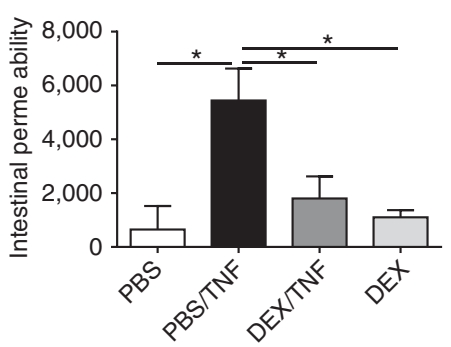

Figure 7 Dexamethasone (DEX) pretreatment protects against tumor necrosis factor (TNF)-induced intestinal epithelial cell (IEC) effects. (a) Muc 2 stainings (red) counterstained with 4',6-diamidino-2-phenylindole (DAPI; blue) on ileal sections of $30 \mu \mathrm{g}$ TNF-treated mice (left) and mice pretreated with $\operatorname{DEX}(500 \mu \mathrm{g},-30 \mathrm{~min})$ and injected with $30 \mu \mathrm{g}$ TNF (right) $8 \mathrm{~h}$ after TNF injection. (b) Muc 2 staining of TNF and DEX + TNF sections $(n=3 \mathrm{mice}$ and $\geq 4$ sections/mouse) was scored by four neutral observers. (c) Relative increase in fluorescence in plasma of phosphate-buffered saline (PBS)-treated, TNFtreated, DEX/TNF-treated, and DEX-treated mice orally gavaged with $4 \mathrm{kDa}$ fluorescein isothiocyanate (FITC-dextran) and injected with TNF ( $n \geq 9$ for TNF-injected mice and $n \geq 5$ for PBS- and DEX-treated mice). (c) Representative transmission electron microscopy (TEM) images of a goblet (left) and Paneth cell (right) in the ileum of DEX-treated P55 mice $8 \mathrm{~h}$ after $30 \mu \mathrm{g}$ TNF challenge. A single Paneth cell is circled by the dotted red line. (d) Quantification of the number of granules in Paneth cells $8 \mathrm{~h}$ after TNF challenge in P55 + I + (black) and DEX-treated P $55+/+$ ileal sections, counted on representative images by a neutral observer ( $n=2$ mice per genotype, $\geq 8$ images per mouse). (e) Measurement of intestinal permeability expressed as relative increase in fluorescence in plasma of PBS- or DEX-pretreated P55 $+/+$ mice orally gavaged with $4 \mathrm{kDa}$ FITC-dextran and injected with $30 \mu \mathrm{g}$ $\operatorname{TNF}\left(n=9\right.$ for TNF-injected mice and $n \geq 5$ for untreated mice). ${ }^{\star} 0.01 \leq P<0.05 ;{ }^{* *} 0.001 \leq P<0.01 ;{ }^{* \star \star} P<0.001$. 
of goblet and Paneth cells $8 \mathrm{~h}$ after TNF injection indicated that DEX treatment protected against TNF-induced ER stress and dysfunction (Figure 7c,d). Pretreatment of mice with DEX also significantly protected against TNF-induced intestinal permeability (Figure 7e) and against the consequent bacterial contamination in liver, lung, and mesenteric lymph nodes (Supplementary Figure 7C-E).

\section{DISCUSSION}

Recent publications reported that systemic toxicity could be induced in a P55-dependent manner by specific sensitization of the intestinal epithelium. Vereecke et al. ${ }^{33}$ reported that IECspecific deficiency of the NF- $\mathrm{KB}$-inhibiting protein A20 severely sensitizes mice to systemic TNF-induced lethal inflammation. Interestingly, when these mice were pretreated with broad-spectrum antibiotics, systemic toxicity could be prevented, suggesting that the intestinal flora plays an important role in this systemic toxicity model. Guma et al..$^{40}$ generated mice with IEC-specific expression of a constitutively active IKK $\beta$, leading to constant NF- $\kappa B$ activation. Injection of an otherwise sublethal dose of endotoxin resulted in IEC apoptosis, intestinal barrier disruption, and bacterial translocation, all of which were found to be TNF and P55 dependent and caused high mortality rates. Both studies suggest that an exaggerated inflammatory response in the intestine can both initiate and drive systemic inflammation. This idea is not new and has already been postulated in sepsis research, where the gut has been described as "the motor of sepsis". ${ }^{41}$

In a previous paper we reported that TNF-induced lethal inflammation is strictly P55 dependent and extremely sensitive to P55 expression levels, as P55 $+/$ - mice were protected against TNF over a wide dose range. ${ }^{29}$ In addition, we generated solid evidence for the involvement of IEC in TNF toxicity: (i) conditional IEC-specific P55 reactivation mutants (expressing P55 + / + levels in IEC cells, in a P55 + / - background) were sensitive to TNF-induced lethality; and (ii) conditional IECspecific P55-deficient mice were protected against TNF lethality. ${ }^{29}$ Here, we investigated the molecular mechanisms of TNF toxicity, focusing on the effects on IECs.

Cell death in the intestinal epithelium is often used as a measure of epithelial barrier dysfunction, ${ }^{4,42,43}$ but the exact mechanism and implications are still unclear. Surprisingly, the induction of intestinal damage and apoptosis was identical in $\mathrm{P} 55+/+$ and P55 $+/$ - IECs, indicating that TNF-induced damage and apoptosis in the gut has no direct relation to the final lethal outcome. ${ }^{29}$ This finding is endorsed by our previous work that came to similar conclusions based on the failure of TNF to induce apoptotic cell death in caspase-3-deficient mice that were not protected against TNF-induced lethal systemic inflammatory response syndrome. ${ }^{44}$ Based on our search for intestinal parameters that, in contrast to damage and cell death, do differ between TNF-challenged P55 $+/+$ and P55 $+/-$ mice, we investigated the contribution of other IEC types involved in TNF toxicity. Our results suggest that TNF injection leads to the activation of three crucial mechanisms in IECs leading to TNF toxicity: (i) ER stress, (ii) goblet and Paneth cell dysfunction, and (iii) intestinal-flora-dependent intestinal leakage.

(i) ER stress: Intestinal secretory cells, such as goblet and Paneth cells, are susceptible to ER stress because they produce large amounts of complex proteins involved in mucosal defense. ${ }^{17}$ The involvement of ER stress in the induction of intestinal inflammation and IBD is well known from the study of mice deficient in the important ER stress regulating proteins Agr $2,{ }^{27}$ spliced Xbp $1,{ }^{25}$ and IRE $1 .{ }^{45}$ In addition, a study on mice expressing mutated Muc 2 concluded that increased ER stress and absence of functional Muc 2 release leads to strong sensitization in intestinal inflammation and IBD-related models. ${ }^{46}$ ER stress in these cells can cause additional intestinal inflammation by direct proinflammatory gene induction, and by reducing the efficacy of the mucosal barrier because of reduced production of mucins. Our data indicate that TNF, a well-known mediator of intestinal inflammation, can induce ER stress in both goblet and Paneth cells. Both cell types contained ER with disturbed and dilated morphology after TNF stimulation. In addition, goblet cells were unable to refill with mucus granules and showed upregulation of key ER stress genes, whereas Paneth cells had a reduced number of antibacterial granules. The TNF-induced dysfunction of both goblet and Paneth cells severely compromises the function of the mucosal barrier leading to increased bacterial-epithelial contacts.

(ii) Goblet and Paneth cell dysfunction: In vitro studies have indicated that TNF stimulation activates goblet cells, leading to rapid release of the mucus-containing granules as well as de novo expression of Muc 2 to replenish the mucus reserves. ${ }^{47}$ Interestingly, a study focusing on necrotizing enterocolitis identified TNFR1 as the responsible receptor for TNF-induced mucus depletion in goblet cells. ${ }^{48}$ Our data show severe mucus depletion in $\mathrm{P} 55+/+$ IECs following TNF injection, as indicated by the $\mathrm{AB}$ and Muc 2 stainings. The data obtained from the reactivation mutants suggest that this is a direct TNF-induced effect on the IECs. A similar inflammationinduced mucus depletion was also observed after endotoxin challenge in both rats and mice, resulting in increased bacterial adhesion to the mucosa and increased bacterial penetration. ${ }^{32,49,50}$ Pretreatment of mice with the mucus-depleting agent pilocarpine severely sensitized them to TNF toxicity. Similar observations were made in rats treated with pilocarpine in which intestinal permeability was enhanced because of mucus depletion, ${ }^{36}$ and in mice in which pilocarpine treatment sensitized for LPS-induced toxicity. ${ }^{49}$ Specific deficiency of Muc 2 in mice leads to spontaneous development of colitis, confirming its important role in prevention of intestinal inflammation. ${ }^{20}$ Moreover, depletion of mucus ${ }^{51}$ as well as intestinal permeability ${ }^{52}$ are also observed in IBD and can be treated with antiTNF therapy ${ }^{53}$ Next to goblet cells, Paneth cells also show signs of severe dysfunction, characterized by the induction of ER stress, the loss of granules, and loss of cellular integrity. Similar mitochondrial dysfunction, extensive ER abnormalities, and a dramatic reduction in stored granules of Paneth cells clearly are recurring events in intestinal inflammation, ${ }^{54}$ and are also observed in IBD, a strongly TNF-driven pathology. 
(iii) Intestinal permeability: Induction of intestinal permeability was found to depend on both mucus depletion and the presence of intestinal flora, suggesting a two-step mechanism with an initial trigger such as TNF allowing increased bacteriaIEC interactions, followed by an IEC-dependent response to this trigger. A similar mechanism was proposed for the induction of IBD-like intestinal inflammation. ${ }^{55,56}$ In both of these studies, the initial stimulus was TNF-induced damage to the IEC, whereas the second stimulus was Myd88 dependent. A similar two-step model was also proposed for dextran sulfate sodium-induced colitis. ${ }^{57}$

We observed that treatment with the potent anti-inflammatory glucocorticoid analog DEX protects against TNF-induced toxicity and Paneth and goblet cell dysfunction. This might indicate that the observed TNF-induced effects in IECs are driven by inflammatory signaling. However, although DEX treatment did not affect TNF-induced cell death induction in the small intestine, glucocorticoids were reported to be involved in multiple molecular mechanism affecting intestinal barrier function. Besides their well-known anti-inflammatory activity, glucocorticoids can inhibit ER stress by induction of ERAD genes, ${ }^{58}$ and they can strengthen the tight junctions by inhibition of TNF-induced MLCK expression. ${ }^{59}$ These data indicate that glucocorticoids prevent intestinal barrier dysfunction at multiple levels.

We propose the hypothesis depicted in Figure 8. In conclusion, we identified P55-driven signaling in IECs as a crucial component of systemic TNF toxicity that appears to be mediated by goblet and Paneth cell dysfunction, increased bacterial stimulation of IECs, induction of gut permeability, and bacterial spread. As all these toxic effects were absent in P55 + / - mice, our data suggest that targeting P55 specifically in the IEC compartment might strongly protect against TNFmediated intestinal pathologies.

\section{METHODS}

Mice. C57BL/6J, $(\mathrm{P} 55+/+)$ mice matched for gender and age were purchased from Janvier (Le Genest, France) or bred in our own specified pathogen-free facility. P55-/- mice produced by targeted gene deletion ${ }^{60}$ were purchased from The Jackson Laboratories (Bar Harbor, ME). P55 floxed cNeo mice ${ }^{13}$ were a kind gift from Dr G. Kollias (Alexander Fleming Biomedical Sciences Research Center, Vari, Greece). All P55-mutant mice were backcrossed to C57BL/6 background for more than 10 generations and bred in our specified pathogen-free animal facility. For specific reactivation in the IECs, we used Villin Cre transgene mice. ${ }^{61}$ Math $1 \mathrm{flx} / \mathrm{flx}$ mice were generated by Dr Huda Zoghbi (Baylor College of Medicine, Houston, TX) and kindly provided to us (Professor B. Hassan, KU Leuven, Laboratory of Neurogenetics, Leuven, Belgium) and were kept in a conventional facility. All mice were used at the age of 8-16 weeks. All experiments were approved by the ethics committee of Ghent University.

Injections, monitoring, and sampling. Recombinant mouse TNF was produced in Escherichia coli and purified in our laboratories with no detectable endotoxin contamination. Recombinant mouse TNF was

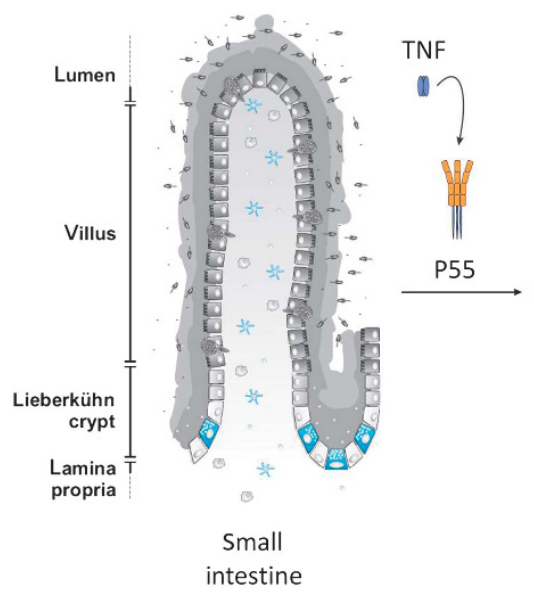

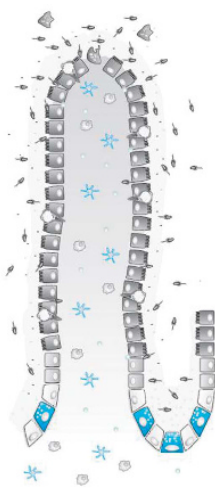

ER stress

mucus depletion

Goblet cell dysfunction

Paneth cell dysfunction

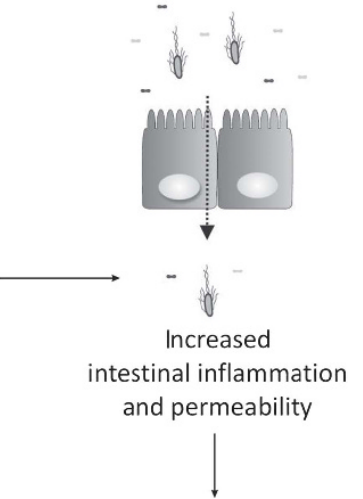

Systemic

inflammation

\begin{tabular}{|c|c|c|c|c|}
\hline >od & Bacteria & Goblet cell & & Dentritic cell \\
\hline 0 & Epithelial cell & Stem cell & 9 & Macrophage \\
\hline 癌 & Paneth cell & Lymphoid cell & $\infty$ & DAMPS \\
\hline 0 & Transit amplifying cell & & - & PAMPS \\
\hline
\end{tabular}

Figure 8 Hypothesis figure. Injection of tumor necrosis factor (TNF) strongly activates goblet cells, causing rapid secretion of mucus as well as increased mucus production. ${ }^{47}$ However, because of exaggerated stimulation in P $55+1+$ mice, goblet cells become dysfunctional, endoplasmic reticulum (ER) stress is induced, and mucus production is no longer replenished, leading to sustained mucus depletion. In addition, Paneth cell function is disturbed, and the consequent reduction in the synthesis of antimicrobial products leaves the door open to bacterial adhesion and infiltration. ${ }^{24}$ Because of goblet and Paneth cell dysfunction, the intestinal flora can easily interact with the epithelial surfaces, causing intestinal permeability and bacterial translocation. This results in systemic inflammation. In contrast, in P55 + / - mice, goblet and Paneth cells remain functional, as reflected by the absence of ER stress. Consequently, the interactions between the intestinal flora and mucosa remain limited, intestinal integrity is maintained, and no systemic toxicity is induced. DAMP, danger-associated molecular pattern; PAMP, pathogen-associated molecular pattern. 
diluted in endotoxin-free PBS and injected intraperitoneally or intravenously in a volume of $0.2 \mathrm{ml}$. Mucus was depleted by treatment with pilocarpine, as previously described: ${ }^{36}$ mice were injected with of pilocarpine (Sigma, Diegem, Belgium) at $160 \mathrm{mg} \mathrm{kg}^{-1}$ (in $200 \mu \mathrm{l} \mathrm{PBS}$ per injection) 45 min before TNF injection. For DEX pretreatment, mice were pretreated with DEX $(500 \mu \mathrm{g}) 30 \mathrm{~min}$ before TNF challenge. Rectal body temperature was recorded with an electric thermometer. Plasma samples and tissue samples of small intestine (ileum) were obtained at designated times after injection. Blood was obtained by cardiac puncture. For the generation of goblet- and Paneth celldepleted mice, the cytochrome $P 450$ Cre enzyme was activated by a single intraperitoneal injection of $200 \mu \mathrm{l}$ of $\beta$-naphthoflavone dissolved in corn oil ( $10 \mathrm{mg} \mathrm{ml}^{-1}$; Sigma) in Math1 flx/flx mice. ${ }^{35}$ After 2 weeks, mice were injected with TNF.

Cytokine/chemokine measurements. Quantification of cytokines and chemokines was performed using the Bio-Plex cytokine assays (Bio-Rad, Eke, Belgium) or the cytometric bead array (R\&D Systems, Abingdon, UK), according to the manufacturers' instructions. In addition, IL- 6 levels after antibiotics treatment were determined by bio-assay as previously described. ${ }^{62}$

Histopathology of small intestine. Tissues were fixed with paraformaldehyde, embedded in paraffin, sectioned at $4 \mu \mathrm{m}$, and stained with hematoxylin (Fluka, Diegem, Belgium) and eosin (Merck, Leuven, Belgium) (hematoxylin and eosin). The degree of damage was evaluated on entire organ sections by four observers in a blinded manner using the validated necrotizing enterocolitis scoring system. ${ }^{30}$ Intestinal damage is characterized by decreased villus height, epithelial cell death at the villus top, and loss of mucus layer and goblet cells. Taking into account all histological features, a damage score ranging from 0 (normal) to 4 (abnormal) was given to each mouse. Paraformaldehyde-fixed, paraffin-embedded sections were also used for Muc 2 staining (1:200; rabbit monoclonal antibody sc-15334; Santa Cruz Biotechnology, Santa Cruz, Heidelberg, Germany) that was detected with anti-rabbit Alexa 555 (1:400; Invitrogen, Merelbeke, Belgium), and for Lysozyme C staining (1:300; goat polyclonal IgG; sc27958; Santa Cruz, Heidelberg, Germany) that was detected with antigoat Alexa 555 (1:400; Invitrogen).

For staining of the mucus layer and bacteria in the small intestine, sligthly thicker sections of $20 \mu \mathrm{m}$ were prepared and fixed with Carnoy's fixative. Staining of Muc 2 was performed as described above but detected with anti-goat Alexa 633. Bacteria were stained with the Cy3-labeled universal bacterial fluorescence in situ hybridization probe EUB338 (5'-GCTGCCTCCCGTAGGAGT-3'). The provided images are snapshots of three-dimensional reconstructed Z-stacks using Volocity software. (PerkinElmer, Zaventem, Belgium).

Apoptosis was identified by TUNEL (Fluorescein In Situ Cell Death Detection Kit; Roche, Vilvoorde, Belgium) following the manufacturer's instructions. Sections were counterstained with 4',6-diamidino2-phenylindole.

For detection of apoptotic cells in the lumen of the intestine, mice were fed sugar water for $12 \mathrm{~h}$, and total small intestine was removed and flushed with $10 \mathrm{ml}$ PBS. The flow-through was passed through a nylon cell strainer $(70 \mu \mathrm{m})$ to remove debris. Cells were stained with Trypan blue and counted using a standard Bürker chamber.

Electron microscopy. The excised ileum was fixed in a solution of $0.3 \%$ glutaraldehyde and $2.5 \%$ formaldehyde dissolved in $0.1 \mathrm{~m}$ sodium cacodylate buffer containing $20 \mathrm{mg}$ per $100 \mathrm{ml} \mathrm{CaCl}_{2}$. Fixed specimens were dehydrated through a graded ethanol series and embedded in LRWhite (Aurion, Wageningen, The Netherlands) for goblet cell analysis and in Spurr for Paneth cells (Aurion). Ultrathin sections of a gold interference color were cut using an ultramicrotome (Leica EM UC6; Leica, Diegem, Antwerp) and poststained with uranyl acetate for $40 \mathrm{~min}$ and lead citrate for $7 \mathrm{~min}$ in a Leica EM AC20. Sections were collected on formvar-coated copper slot grids and viewed with TEM (JEOL 1010; JEOL, Tokyo, Japan).
Intestinal permeability. Fluorescein isothiocyanate-labeled dextran (4 kDa, Sigma) was administered to mice by gavage at $150 \mathrm{mg} \mathrm{kg}^{-1}$ body weight. After $5 \mathrm{~h}$, blood obtained by heart puncture was collected in EDTA-coated tubes (Sarstedt, Hoogstraten, Belgium) and plasma was prepared. Leakage of fluorescein isothiocyanate-labeled dextran into the circulation was determined by measurement of the fluorescence with $\lambda_{\text {ex }}$ and $\lambda_{\text {em }}$ at 488 and $520 \mathrm{~nm}$. Values were normalized to the lowest value.

Depletion of commensal intestinal bacteria. For antibiotic-mediated depletion of commensal bacteria, mice were treated with $200 \mathrm{mgl}^{-1}$ ciprofloxacin (Sigma), $1 \mathrm{gl}^{-1}$ ampicillin (Sigma), $1 \mathrm{gl}^{-1}$ metronidazole (Sigma), and $500 \mathrm{mgl}^{-1}$ vancomycin (Duchefa Biochemie, Haarlem, The Netherlands) in drinking water. After 2 weeks, the presence of colonic microflora was determined by culturing fecal samples in brain heart infusion (BD, Erembodegem, Belgium) and in thioglycollate medium (Sigma).

Detection of bacteria in different organs. P $55+/+$ and P55 $+/-$ mice were injected with PBS or $30 \mu \mathrm{g}$ TNF and killed $18 \mathrm{~h}$ later. Lysates of liver, lung, mesenteric lymph nodes, and blood were cultured on Tryptic Soy Agar plates and colonies were counted after $24 \mathrm{~h}$.

Cell culture. HT29-MTX goblet cells were a kind gift from Dr Thécla Lesuffleur (INSERM UMR S 938, Paris, France). ${ }^{34}$ They were grown in Dulbecco's modified Eagle's medium supplemented with $25 \mathrm{~mm}$ glucose and $10 \%$ fetal bovine serum. Cells were seeded in six-well plates. After 21 days, $2,000 \mathrm{U} \mathrm{ml}^{-1}$ recombinant human TNF was added and samples were collected at different times, followed by RNA isolation. For the siRNA experiment, cells were transfected using Lipofectamine 2000 (Invitrogen) with a P55-specific siRNA and a control siRNA ( 80 pmol per well; Dharmacon, Diegem, Belgium). After $24 \mathrm{~h}$, TNF was added and RNA samples were isolated $6 \mathrm{~h}$ after stimulation.

Quantitative real-time PCR. Organs were stored in RNALater (Ambion, Ghent, Belgium) and RNA was isolated using the RNeasy Mini Kit (Qiagen, Antwerp, Belgium). Complementary DNA was synthesized by the iScript cDNA Synthesis Kit (Bio-Rad). Quantitative real-time PCR was performed on the Light Cycler 480 system (Roche) using the LightCycler 480 SYBR Green I Master (Roche,Vilvoorde, Belgium). Expression levels were normalized to the expression of the two most stable housekeeping genes that were determined for each organ using the geNorm House Keeping Gene Selection Software (QBase, Biogazelle, Ghent). ${ }^{63}$

Statistics. Data are presented as means \pm s.e.m. Data were analyzed with an unpaired Mann-Whitney $U$-test, unless mentioned differently. Survival curves were compared using a log-rank test. Significance levels were calculated for differences from the corresponding $0 \mathrm{~h}$ time point and/or between $\mathrm{P} 55+/+$ and $\mathrm{P} 55+/-$ mice, as indicated: ${ }^{\star} 0.01 \leq P<0.05 ;{ }^{\star *} 0.001 \leq P<0.01$; and ${ }^{\star * *} P<0.001$.

SUPPLEMENTARY MATERIAL is linked to the online version of the paper at http://www.nature.com/mi

\section{ACKNOWLEDGMENTS}

We thank Dr George Kollias from Alexander Fleming Biomedical Sciences Research Center (Vari, Greece) for kindly providing the conditional TNFR1 reactivation mice. We thank Dr Amin Bredan for editing the manuscript. The work was supported by FWO and IWT Vlaanderen, Belgium, and by the IUAP network 7/32. F.V.H and R.E.V are supported by FWO Vlaanderen, Belgium. L.G is supported by a grant from IWT, Belgium. S. L was supported by a grant from "Stichting tegen Kanker," Belgium.

\section{DISCLOSURE}

The authors declared no conflict of interest.

(c) 2015 Society for Mucosal Immunology 


\section{REFERENCES}

1. Tracey, K.J. et al. Anti-cachectin/TNF monoclonal antibodies prevent septic shock during lethal bacteraemia. Nature 330, 662-664 (1987).

2. Feldmann, M. \& Maini, R.N. Lasker Clinical Medical Research Award. TNF defined as a therapeutic target for rheumatoid arthritis and other autoimmune diseases. Nat. Med. 9, 1245-1250 (2003).

3. van Dullemen, H.M. et al. Treatment of Crohn's disease with anti-tumor necrosis factor chimeric monoclonal antibody (cA2). Gastroenterology 109, 129-135 (1995).

4. Huys, L. et al. Type I interferon drives tumor necrosis factor-induced lethal shock. J. Exp. Med. 206, 1873-1882 (2009).

5. Takahashi, N. et al. IL-17 produced by Paneth cells drives TNF-induced shock. J. Exp. Med. 205, 1755-1761 (2008).

6. Everaerdt, B., Brouckaert, P. \& Fiers, W. Recombinant IL-1 receptor antagonist protects against TNF-induced lethality in mice. J. Immunol. 152, 5041-5049 (1994)

7. Vandenbroucke, R.E. \& Libert, C. Is there new hope for therapeutic matrix metalloproteinase inhibition? Nat. Rev. Drug. Discov. advance online publication, 7 November 2014 (e-pub ahead of print).

8. Tracey, K.J. et al. Shock and tissue injury induced by recombinant human cachectin. Science 234, 470-474 (1986).

9. Piguet, P.F., Vesin, C., Guo, J., Donati, Y. \& Barazzone, C. TNF-induced enterocyte apoptosis in mice is mediated by the TNF receptor 1 and does not require p53. Eur. J. Immunol. 28, 3499-3505 (1998).

10. Halpern, M.D. et al. Reduction of experimental necrotizing enterocolitis with anti-TNF-alpha. Am. J. Physiol. Gastrointest. Liver Physiol. 290, G757-G764 (2006).

11. Taylor, C.T., Dzus, A.L. \& Colgan, S.P. Autocrine regulation of epithelial permeability by hypoxia: role for polarized release of tumor necrosis factor alpha. Gastroenterology 114, 657-668 (1998).

12. Van Hauwermeiren, F. et al. Safe TNF-based antitumor therapy following p55TNFR reduction in intestinal epithelium. J. Clin. Invest. 123, 2590-2603 (2013).

13. Victoratos, P. et al. FDC-specific functions of p55TNFR and IKK2 in the development of FDC networks and of antibody responses. Immunity $\mathbf{2 4}$ 65-77 (2006).

14. van der Flier, L.G. \& Clevers, H. Stem cells, self-renewal, and differentiation in the intestinal epithelium. Annu. Rev. Physiol. 71, 241-260 (2009).

15. Marchiando, A.M. et al. Caveolin-1-dependent occludin endocytosis is required for TNF-induced tight junction regulation in vivo. J. Cell Biol. 189, 111-126 (2010).

16. Johansson, M.E., Thomsson, K.A. \& Hansson, G.C. Proteomic analyses of the two mucus layers of the colon barrier reveal that their main component, the Muc2 mucin, is strongly bound to the Fcgbp protein. J. Proteome Res. 8, 3549-3557 (2009).

17. McGuckin, M.A., Eri, R.D., Das, I., Lourie, R. \& Florin, T.H. ER stress and the unfolded protein response in intestinal inflammation. Am. J. Physiol. Gastrointest. Liver Physiol. 298, G820-G832 (2010).

18. Specian, R.D. \& Oliver, M.G. Functional biology of intestinal goblet cells. Am. J. Physiol. 260 (2 Pt 1), C183-C193 (1991).

19. Deplancke, B. \& Gaskins, H.R. Microbial modulation of innate defense: goblet cells and the intestinal mucus layer. Am. J. Clin. Nutr. 73, 1131S-1141S (2001).

20. Van der Sluis, M. et al. Muc2-deficient mice spontaneously develop colitis, indicating that MUC2 is critical for colonic protection. Gastroenterology 131, 117-129 (2006).

21. Shan, M. et al. Mucus enhances gut homeostasis and oral tolerance by delivering immunoregulatory signals. Science 342, 447-453 (2013).

22. Sato, T. et al. Paneth cells constitute the niche for Lgr5 stem cells in intestinal crypts. Nature 469, 415-418 (2011).

23. Bevins, C.L. \& Salzman, N.H. Paneth cells, antimicrobial peptides and maintenance of intestinal homeostasis. Nat. Rev. Microbiol. 9, 356-368 (2011).

24. Vaishnava, S., Behrendt, C.L., Ismail, A.S., Eckmann, L. \& Hooper, L.V. Paneth cells directly sense gut commensals and maintain homeostasis at the intestinal host-microbial interface. Proc. Natl. Acad. Sci. USA 105, 20858-20863 (2008).

25. Kaser, A. et al. XBP1 links ER stress to intestinal inflammation and confers genetic risk for human inflammatory bowel disease. Cell 134, 743-756 (2008)

26. Namba, T. et al. Positive role of CCAAT/enhancer-binding protein homologous protein, a transcription factor involved in the endoplasmic reticulum stress response in the development of colitis. Am. J. Pathol. 174, 1786-1798 (2009).

27. Zhao, F. et al. Disruption of Paneth and goblet cell homeostasis and increased endoplasmic reticulum stress in Agr2-/- mice. Dev. Biol. 338, 270-279 (2010).

28. Adolph, T.E. et al. Paneth cells as a site of origin for intestinal inflammation. Nature 503, 272-276 (2013).

29. Hauwermeiren, F.V. et al. Safe TNF-based antitumor therapy following p55TNFR reduction in intestinal epithelium. J. Clin. Invest. 123, 2590-2603 (2013).

30. Halpern, M.D. et al. Hepatic inflammatory mediators contribute to intestinal damage in necrotizing enterocolitis. Am. J. Physiol. Gastrointest. Liver Physiol. 284, G695-G702 (2003).

31. Costantini, T.W. et al. Quantitative assessment of intestinal injury using a novel in vivo, near-infrared imaging technique. Mol. Imaging 9, 30-39 (2010).

32. Goldman, G., Soffer, D., Heller, L., Aderka, D., Lahat, A. \& Klausner, J.M. Tumour necrosis factor mediates bacterial translocation after haemorrhagic shock and endotoxaemia. Eur. J. Surg. 167, 299-304 (2001).

33. Vereecke, L. et al. Enterocyte-specific A20 deficiency sensitizes to tumor necrosis factor-induced toxicity and experimental colitis. J. Exp. Med. 207, 1513-1523 (2010).

34. Lesuffleur, T., Barbat, A., Dussaulx, E. \& Zweibaum, A. Growth adaptation to methotrexate of HT-29 human colon carcinoma cells is associated with their ability to differentiate into columnar absorptive and mucus-secreting cells. Cancer Res. 50, 6334-6343 (1990).

35. van Es, J.H., de Geest, N., van de Born, M., Clevers, H. \& Hassan, B.A. Intestinal stem cells lacking the Math1 tumour suppressor are refractory to Notch inhibitors. Nat. Commun. 1, 18 (2010).

36. Albanese, C.T. et al. Role of intestinal mucus in transepithelial passage of bacteria across the intact ileum in vitro. Surgery 116, 76-82 (1994).

37. Ohama, T. et al. Intestinal inflammation downregulates smooth muscle CPI-17 through induction of TNF-alpha and causes motility disorders. Am. J. Physiol. Gastrointest. Liver Physiol. 292, G1429-G1438 (2007).

38. Libert, C., Van Bladel, S., Brouckaert, P. \& Fiers, W. The influence of modulating substances on tumor necrosis factor and interleukin-6 levels after injection of murine tumor necrosis factor or lipopolysaccharide in mice. J. Immunother. 10, 227-235 (1991).

39. Van Bogaert, T. et al. Tumor necrosis factor inhibits glucocorticoid receptor function in mice: a strong signal toward lethal shock. J. Biol. Chem. 286, 26555-26567 (2011).

40. Guma, M. et al. Constitutive intestinal NF-kappaB does not trigger destructive inflammation unless accompanied by MAPK activation. J. Exp. Med. 208, 1889-1900 (2011).

41. Swank, G.M. \& Deitch, E.A. Role of the gut in multiple organ failure: bacterial translocation and permeability changes. World J. Surg. 20, 411-417 (1996).

42. Waelput, W., Broekaert, D., Vandekerckhove, J., Brouckaert, P., Tavernier, J. \& Libert, C. A mediator role for metallothionein in tumor necrosis factorinduced lethal shock. J. Exp. Med. 194, 1617-1624 (2001).

43. Van Molle, W. et al. HSP70 protects against TNF-induced lethal inflammatory shock. Immunity 16, 685-695 (2002).

44. Duprez, L. et al. RIP kinase-dependent necrosis drives lethal systemic inflammatory response syndrome. Immunity 35, 908-918 (2011).

45. Bertolotti, A. et al. Increased sensitivity to dextran sodium sulfate colitis in IRE1beta-deficient mice. J. Clin. Invest. 107, 585-593 (2001).

46. Heazlewood, C.K. et al. Aberrant mucin assembly in mice causes endoplasmic reticulum stress and spontaneous inflammation resembling ulcerative colitis. PLoS Med. 5, e54 (2008).

47. Enss, M.L. et al. Proinflammatory cytokines trigger MUC gene expression and mucin release in the intestinal cancer cell line LS180. Inflamm. Res. 49 162-169 (2000).

48. McElroy, S.J., Prince, L.S., Weitkamp, J.H., Reese, J., Slaughter, J.C. \& Polk, D.B. Tumor necrosis factor receptor 1-dependent depletion of mucus in immature small intestine: a potential role in neonatal necrotizing enterocolitis. Am. J. Physiol. Gastrointest. Liver Physiol. 301, G656-G666 (2011).

49. Vandenbroucke, R.E. et al. Matrix metalloproteinase 13 modulates intestinal epithelial barrier integrity in inflammatory diseases by activating TNF. EMBO Mol. Med. 5, 932-948 (2013). 


\section{ARTICLES}

50. Vandenbroucke, R.E., Vanlaere, I., Van Hauwermeiren, F., Van Wonterghem, E., Wilson, C. \& Libert, C. Pro-inflammatory effects of matrix metalloproteinase 7 in acute inflammation. Mucosal Immunol. 7, 579-588 (2013).

51. Strugala, V., Dettmar, P.W. \& Pearson, J.P. Thickness and continuity of the adherent colonic mucus barrier in active and quiescent ulcerative colitis and Crohn's disease. Int. J. Clin. Pract. 62, 762-769 (2008).

52. Katz, K.D. et al. Intestinal permeability in patients with Crohn's disease and their healthy relatives. Gastroenterology 97, 927-931 (1989).

53. Suenaert, P. et al. Anti-tumor necrosis factor treatment restores the gut barrier in Crohn's disease. Am. J. Gastroenterol. 97, 2000-2004 (2002).

54. Cadwell, K. et al. A key role for autophagy and the autophagy gene Atg1611 in mouse and human intestinal Paneth cells. Nature 456, 259-263 (2008).

55. Nenci, A. et al. Epithelial NEMO links innate immunity to chronic intestinal inflammation. Nature 446, 557-561 (2007).

56. Welz, P.S. et al. FADD prevents RIP3-mediated epithelial cell necrosis and chronic intestinal inflammation. Nature 477, 330-334 (2011).

57. Johansson, M.E. et al. Bacteria penetrate the inner mucus layer before inflammation in the dextran sulfate colitis model. PLoS One 5, e12238 (2010).
58. Das, I. et al. Glucocorticoids alleviate intestinal ER stress by enhancing protein folding and degradation of misfolded proteins. J. Exp. Med. 210, 1201-1216 (2013).

59. Boivin, M.A., Ye, D., Kennedy, J.C., Al-Sadi, R., Shepela, C. \& Ma, T.Y. Mechanism of glucocorticoid regulation of the intestinal tight junction barrier. Am. J. Physiol. Gastrointest. Liver Physiol. 292, G590-G598 (2007).

60. Rothe, J. et al. Mice lacking the tumour necrosis factor receptor 1 are resistant to TNF-mediated toxicity but highly susceptible to infection by Listeria monocytogenes. Nature 364, 798-802 (1993).

61. Madison, B.B., Dunbar, L., Qiao, X.T., Braunstein, K., Braunstein, E. \& Gumucio, D.L. Cis elements of the villin gene control expression in restricted domains of the vertical (crypt) and horizontal (duodenum, cecum) axes of the intestine. J. Biol. Chem. 277, 33275-33283 (2002).

62. Van Snick, J. et al. Purification and NH2-terminal amino acid sequence of a T-cell-derived lymphokine with growth factor activity for B-cell hybridomas. Proc. Natl. Acad. Sci. USA 83, 9679-9683 (1986).

63. Vandesompele, J. et al. Accurate normalization of real-time quantitative RT-PCR data by geometric averaging of multiple internal control genes. Genome Biol. 3, RESEARCH0034 (2002). 